\title{
EDUKITO: propiciando a inclusão digital de Pessoas com Necessidades Educacionais Especiais*
}

\author{
(EDUKITO: aiding digital inclusion process for people with special educational \\ needs)
}

\author{
Liliana Maria Passerino** \\ Lucila M. C. Santarosa***
}

\section{RESUMO}

Este trabalho visa apresentar um ambiente telemático em desenvolvimento pelo NIEE/UFRGS: EDUKITO. Através deste ambiente, que foi projetado baseado na pedagogia por projetos dentro de uma perspectiva sócio-histórica, procura-se propiciar a inclusão digital de pessoas com necessidades educacionais especiais (PNEEs). Assim, iniciamos por uma discussão do conceito de inclusão e de necessidades especiais para posteriormente aprofundar na concepção de ambientes digitais de aprendizagem como ferramentas para a inclusão digital e social de PNEEs, através do trabalho por projetos. Por último, apresentamos o ambiente EDUKITO, descrevendo seus recursos e funcionalidades, em especial as ferramentas que apoiam à ação do sujeito no desenvolvimento de projetos de aprendizagem.

Palavras-chave: inclusão digital, ambiente telemático, pedagogia por projeto, necessidades educacionais especiais

\begin{abstract}
This work presents a digital learning environment called EDUKITO, currently being developed in the NIEE/UFRGS. Through this environment, which is based on the project-oriented pedagogical metodology in a socio-historical perspective, we try to aid the digital inclusion process of people with special educational needs. We start discussing the concepts of social inclusion and special educational needs trying to figure out how they can influence the conception of learning environments which support project-oriented pedagogical metodology. In the last part of the paper we present the EDUKITO environment, showing his functions, resources and facilities, with special focus on the resources that support user's actions in the context of projectlearning development.
\end{abstract}

Keywords: digital inclusion process, digital learning environment, project-oriented pedagogical methodology, specials educational needs.

\section{Inclusão e Necessidades Educacionais Especiais}

O conceito de "necessidades especiais" tem mudado muito ao longo da história até chegar aos nossos dias. Durante a primeira metade do século passado, era equivalente ao conceito de "deficiência" e considerava-se de caracter permanente, sendo possível apenas "adaptar" ou "treinar" a pessoa "deficiente" para viver na sociedade

\footnotetext{
*Adaptado do artigo original apresentado no TISE 2003 - $8^{\circ}$ Taller Internacional de Software Educativo de 24 a 26 de novembro de 2003 em Santiago, Chile.

** Doutoranda no Pós-Graduação Stricto Sensu de Informática na Educação - PGIE/UFRGS. Coordenadora do Núcleo de Atendimento e Pesquisa da ONG RedEspecial-Brasil/ULBRA. Professora de Pós-Graduação em Informática na Educação ULBRA/Canoas. <liliana@pgie.ufrgs.br, lilianap@ulbra.tche.br>

**** Coordenadora do Núcleo de Informática na Educação Especial - NIEE/UFRGS. Presidente da ONG RedEspecial Brasil. Professora e Pesquisadora do Programa de Pós-Graduação Stricto Sensu de Informática na Educação Especial - PGIE/UFRGS. <lucila.santarosa@ufrgs.br, http://www.niee.ufrgs.br>
} 
através de um "tratamento especial", que ficava sob a responsabilidade de instituições especializadas. No início da década de 60, não entanto, a idéia de distúrbios permanentes e imutáveis começou a ser questionada e o conceito de "deficiente" foi sendo substituído pelo de Pessoa com Necessidades Educativas Especiais (PNEE).

Segundo Marchesi e Martin(1993) as PNEEs são pessoas que "...apresentam algum problema de aprendizagem ao longo da sua escolarização e que exige uma atenção mais específica e maiores recursos educacionais do que os necessários para os colegas de suas idade" (p.11, grifo nosso). Note que a noção de recursos educacionais ultrapassa os limites físicos da sala de aula, sendo considerados além de material didático, questões relativas à acessibilidade física e digital, adaptações curriculares e de avaliação, apoio psicopedagógico, novas metodologias, entre outros (Marchesi e Martin, 1993). Paralelamente, Evans (1999), define as PNEE como sendo "... aquelas cujas escolas não podem educar efetivamente sem apoio adicional" (p. 70). Assim, estas definições centram-se nas necessidades educativas especiais do processo educativo, tirando o foco da "deficiência" e apostando num processo inclusivo, que para ser bem sucedido precisa de recursos adicionais, sejam técnicos, humanos ou arquitetônicos

O Brasil, vem realizando um processo de inclusão que teve seu início em 1992 quando uma nova política de fortalecimento da Educação Especial foi estabelecida através da recriação da Secretaria de Educação Especial (SEESP), na estrutura do MEC (Lei 8.490/92). Do ponto de vista social, este fato representou uma mudança positiva para o desenvolvimento de ações educativas para as PNEE e do ponto de vista político, mostrou a preocupação do MEC com relação a oferecer oportunidades para uma educação para todos os cidadãos, incluindo dentro deste contexto aquela parcela da população que sofre sérias discriminações dentro da sociedade. Por volta de 1994, foi lançada a Política Nacional de Educação Especial, que tem norteado as ações do governo brasileiro ${ }^{1}$. A partir de 1995, o MEC incrementou seus esforços para a implantação e implementação da política de educação especial em todo território brasileiro visando expandir e melhorar as ações da Educação Especial, fomentando a integração dos alunos com necessidades educacionais especiais no sistema regular de ensino e o fortalecendo as instituições especializadas para a melhoria do atendimento ao aluno, sempre buscando sua efetiva integração na sociedade. Mas, foi o ano de 1996 que determinou os novos rumos para o atual processo de transformação do sistema educacional brasileiro, ao contribuir, com novos conceitos e idéias sobre essa modalidade de educação escolar e sobre alunos com necessidades especiais, para a elaboração da nova LDB. (Lei 9394/96) e dos Parâmetros Curriculares Nacionais, que redirecionaram e subsidiaram as ações educativas posteriores, que visavam a formação de cidadãos críticos e integrados, mostrando que a Educação Especial é parte integrante da Educação Geral (SEESP, 2001).

Formando parte desse processo de inclusão, encontramos os primeiros trabalhos e pesquisas de utilização da informática na área de Educação Especial no Núcleo de Informática na Educação Especial (NIEE) da Universidade Federal do Rio Grande do Sul (UFRGS). Coordenado pela Dra. Lucila M. Costi Santarosa . O NIEE atua como centro de estudos e pesquisas do uso da tecnologia na educação especial e também no desenvolvimento de ambientes e ferramentas computacionais e formação de recursos humanos (Santarosa, 1999) 
Ao longo das décadas outros centros e estudos foram criados em Universidades e Organizações não governamentais (ONGs) no Brasil todo ${ }^{2}$. Em especial gostaríamos de destacar o trabalho que vem sendo desenvolvido pela ONG RedEspecial Brasil e no qual se insere o presente trabalho. A ONG REDESPECIAL-BR é uma instituição não governamental criada em 1999, que visa entre outras ações a inclusão digital de PNEEs. Filiada à Redespecial Internacional que contempla mais de 21 países ibero-americanos, a REDESPECIAL-BR busca, através das Tecnologias da Informação e Comunicação, melhorar a qualidade de vida de PNEEs, assim como propor e desenvolver estudos, pesquisas e estratégias inovadoras que contribuam para a reabilitação, inclusão social e profissional desta parcela significativa de pessoas na sociedade com dignidade e integralmente.

A metodologia de trabalho que apoia as atividades da ONG REDESPECIAL está embasada na construção de ambientes digitais/virtuais construtivistas, que se fundamentam em teorias que dão suporte a essa construção. Neste sentido, utilizam-se esses ambientes como um recurso para ampliar a comunicação, a linguagem, a autonomia e as trocas entre sujeitos, na construção de conhecimento, visando o seu desenvolvimento nas dimensões cognitivas e sócio-afetivas. Portanto, considera-se o computador como uma ferramenta que pode potencializar a articulação de conhecimentos de áreas diversas e promover um trabalho colaborativo. $\mathrm{O}$ papel do professor, ou de outros profissionais junto à PNEE, é de mediador/facilitador visando o desenvolvimento cognitivo e social dos sujeitos através de atividades socialmente relevantes, que poderão propiciar novas descobertas (Passerino e Santarosa, 2002).

\section{EDUKITO: um ambiente para a Inclusão Digital}

O EDUKITO foi idealizado e projetado como um Ambiente Digital de Aprendizagem (ADA) ${ }^{3}$ que permita o trabalho junto aos alunos através de Projetos de Aprendizagem seguindo a concepção epistemológica embasada na Teoria SócioHistórica.

O ambiente EDUKITO, também foi inspirado no ambiente de Educação a Distância TELEDUC, desenvolvido pelo NIED/Unicamp. Mas, esse ambiente é orientado para a criação, participação e administração de cursos na Web e suas ferramentas voltadas para um público diversificado na sua maioria adultos. (Santarosa et alli, 2001).

O ambiente EDUKITO diferencia-se do TelEduc por ser um ambiente orientado a projetos de aprendizagem, no qual são disponibilizadas e integradas diferentes ferramentas de interação e comunicação, além de espaços para reflexão pessoal e organização de materiais desenvolvido ao longo dos projetos pelos participantes.

Esse ambiente foi planejado para propiciar a inclusão digital na qual PNEEs possam interagir e participar. Dessa forma, o ambiente, busca propiciar a acessibilidade a todos. Por esse motivo, está projetado que em futuras implementações seja atendida a acessibilidade a cegos, entre outros.

A figura 1 apresenta a entrada ao ambiente. Para participar a pessoa tem que fazer um cadastro inicial no qual indicará além de seus dados pessoais, o seu mediador 
que será a pessoa responsável pelo acompanhamento do aluno no ambiente e nas suas atividades dentro dos projetos.

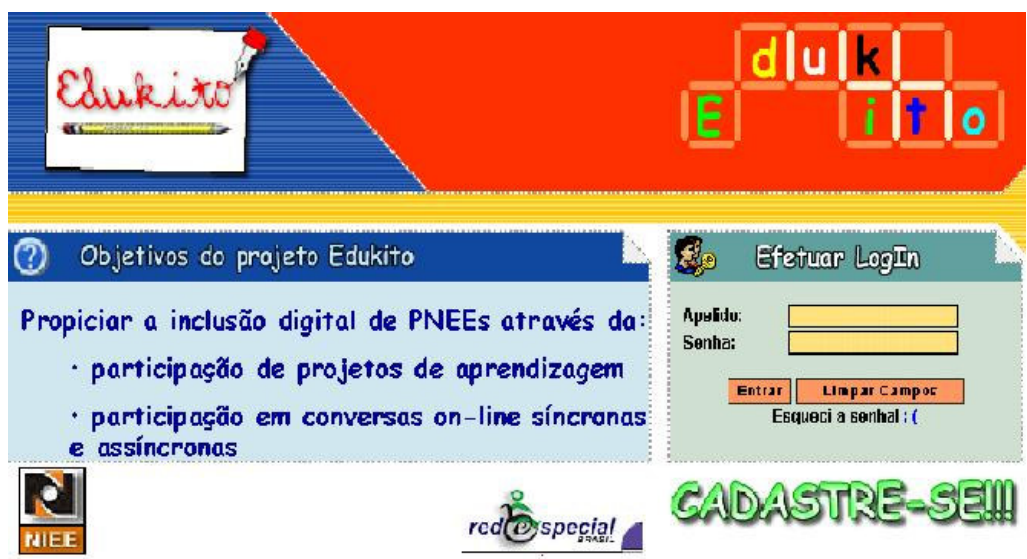

Figura 1 - Tela de Inicial do Edukito

Através de um sistema simplificado de login e senha, o usuário ingressa na área geral, na qual além de poder ver os projetos disponíveis, contém outras ferramentas e serviços para facilitar a comunicação entre os usuários (figura 2). Qualquer usuário do ambiente pode propor novos projetos, se cadastrar nos que estão disponíveis e acessar naqueles nos quais já se cadastrou. Não existe limite para o número de projetos que o aluno pode participar.

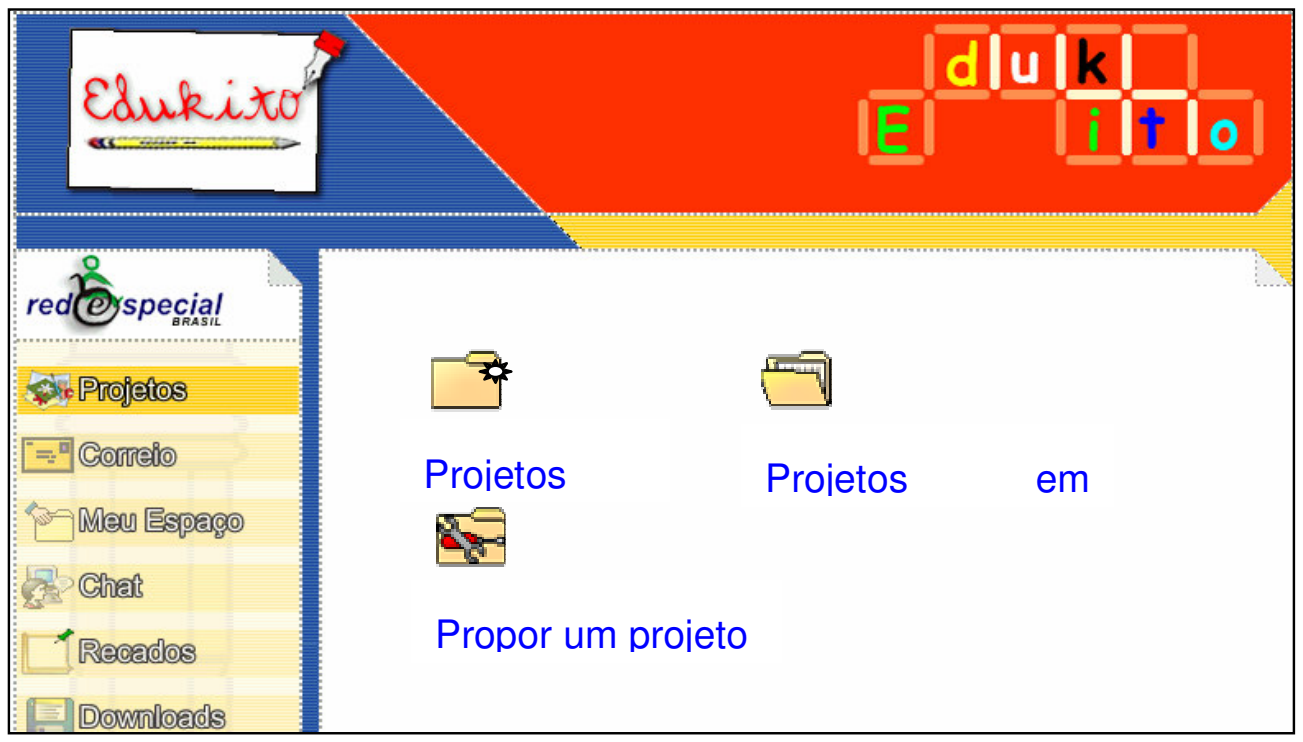

Figura 2 - Área Comum a todos os membros do EDUKITO e entrada aos Projetos

A estrutura interna do EDUKITO pode ser modelada como mostra a figura 3, por conjunto de recursos agrupados pela sua funcionalidade: 


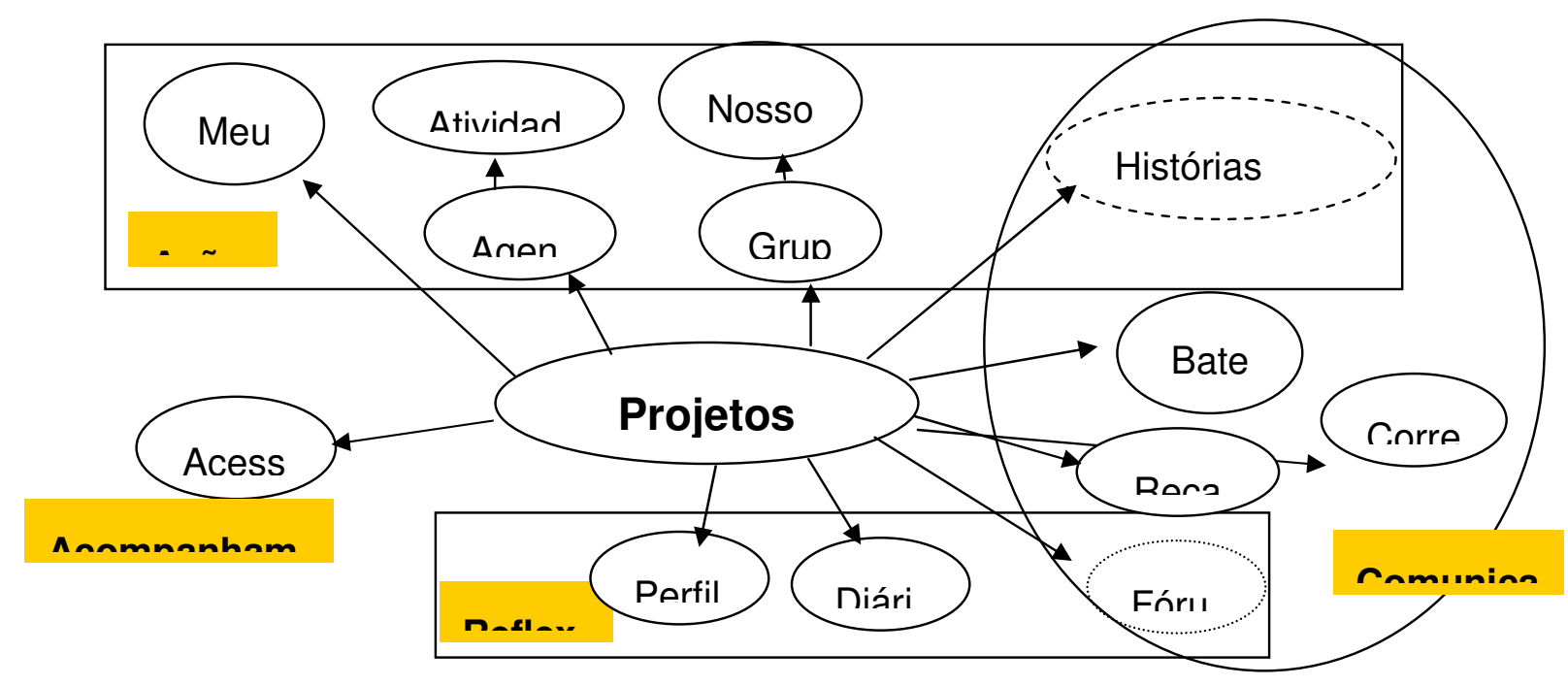

Figura 3 - Representação da Estrutura e Recursos do Edukito

A estrutura do EDUKITO tem, como elemento central, a ferramenta que cria e disponibiliza Projetos. Para apoiar a organização do trabalho, foi criada a ferramenta Agenda. É ali que são publicadas as propostas de trabalho para um determinado projeto. A comunicação entre os participantes e o compartilhamento dos trabalhos desenvolvidos são pontos centrais no desenvolvimento de projetos e por isso são apoiados por ferramentas de comunicação e de colaboração como o Correio, Grupos, Recados, Diário, Bate-Papo etc.

\section{Recursos de Comunicação:}

- Correio: permite a comunicação entre os participantes, a partir de um correio interno do ambiente com as mesmas funcionalidades de um correio tradicional;

- Bate-Papo: são salas de conversas que podem ser criadas por qualquer participante, na versão atual em formato de texto, mas pretende-se incorporar som e imagens, além de dar suporte a videoconferência em próximas versões;

- Recados: este é um espaço para deixar avisos de forma geral para todos os participantes, ou apenas para alguns. Se diferencia do correio pois o recado fica disponível e visível para todos os participantes. Os recados podem ter texto, e gifs (emoticons), também é possível formatar a fonte e o fundo do mesmo;

- Fórum: é possível criar vários fóruns dentro de um projeto, e como no batepapo, qualquer participante pode abrir fóruns e participar dos mesmos;

- Histórias Colaborativas: é um espaço para criação de histórias de forma colaborativa, na qual cada participante pode acrescentar textos ou imagens a uma história grupal. Esta ferramenta não está ainda disponível na versão atual.

\section{Recursos para a Ação:}

- Meu Espaço: é uma área de trabalho, que segue a metáfora do Windows Explorer, na qual é possível armazenar trabalhos referentes aos projetos, ou particulares de cada aluno. $\mathrm{O}$ aluno pode compartilhar ou não esses 
materiais. Existem pastas criadas automaticamente, como por exemplo as pastas dos projetos que cada usuário participa. Mas o aluno pode criar quantas pastas desejar para organizar seu espaço. $\mathrm{O}$ administrador é quem limita o tamanho geral do meu espaço de acordo com as capacidades do servidor no qual o EDUKITO está instalado.

- Agenda: Este recurso é organizado a partir da descrição do projeto feita inicialmente pelo seu criador. Nela são criadas atividades, sugeridas por qualquer participante.

- Atividades: nela são descritas as atividades do projeto, como podem ser criadas por qualquer participante, elas são mostradas por ordem de criação, juntamente com a data/hora e o nome do criador dessa atividade;

- Grupos: neste espaço são definidos os grupos dentro do grande grupo que irão desenvolver o projeto junto. $\mathrm{O}$ aluno que cria um grupo, convida ou outros participantes que podem aceitar ou não formar parte. Como no resto do ambiente, o aluno pode optar por criar um grupo, participar num grupo já existente ou trabalhar individualmente;

- Nosso Espaço: Este é o espaço reservado para o grupo, todos os materiais produzidos pelos membros do grupo podem ser armazenados diretamente neste espaço, ou no Meu Espaço, indicando para ser compartilhado dentro do Nosso Espaço, desta forma o EDUKITO estabelece um link entre ambas ferramentas, sem precisar o usuário sair de uma ferramenta e ir para outra na hora de organizar seus materiais.

\section{Recursos para a Reflexão:}

- Perfil: oferece um espaço para o usuário fornecer uma série de informações pessoais e, se desejar, enviar sua fotografia ou escolher um personagem que o represente (emoticons). Estas informações podem ser consultadas pelos demais usuários do ambiente, propiciando mais um recurso para a aproximação dos participantes através da identificação de interesses comuns.

- Diário: é um espaço reservado para reflexões pessoais com acesso restrito somente ao aluno e o mediador.

\section{Recursos de Acompanhamento:}

- Acessos: são relatórios de acessos quantitativos organizados por ferramentas ou por datas. A finalidade destas ferramentas é auxiliar o mediador no acompanhamento do aluno., mas as ferramentas encontram-se disponíveis para todos os participantes.

- Recursos do Administrador: formam parte do ambiente, mas seu acesso é restrito. Estes recursos permitem realizar backup, autorizar usuários, tornar alunos em mediadores, entre outros.

A área de projetos do EDUKITO é dividida em duas partes (frames). No frame da esquerda encontra-se um menu, onde são disponibilizadas as ferramentas utilizadas durante projeto e, no frame da direita, apresenta-se o conteúdo correspondente à ferramenta selecionada. Muitas das ferramentas da área comum permanecem na área de projeto, complementadas pelas ferramentas específicas que tem por função auxiliar os alunos no desenvolvimento dos projetos. Com relação às ferramentas comuns, elas foram projetadas para serem "sensíveis ao contexto". Assim, a ferramenta correio, por exemplo, dentro de um projeto estará configurada somente com os nomes dos participantes do projeto específico. Enquanto que na área comum as ferramentas de 
comunicação são configuradas para enviar e receber mensagens para todos os participantes do ambiente, mas dentro de um projeto específico, somente os membros do projeto terão acesso a essas informações.

Através do ícone Projetos (figura 2) o aluno poderá verificar os projetos que estão em andamento, os projetos nos quais está cadastrado, os que estão sendo propostos e abertos para cadastro e finalmente a possibilidade do próprio aluno propor um novo projeto. Quando um aluno propõe um projeto deverá fornecer uma breve descrição do mesmo, seus objetivos e o tempo de duração, além de sugerir um mediador (se desejar).

Uma vez proposto o projeto, o mesmo fica disponível para todos os usuários do EDUKITO para inscrição. Quando um aluno ingressa num projeto o aluno terá como acessar a descrição completa do mesmo, a agenda prevista, o cronograma e as atividades sugeridas. Novas atividades podem ser sugeridas por qualquer um dos participantes, mas sempre vinculadas à agenda do projeto. Uma opção de perfil é disponibilizada para o aluno se apresentar e colocar suas expectativas com relação ao projeto. Se o aluno participa de outros projetos esse perfil pode ser compartilhado e se manter igual para todos os projetos nos quais participa.

Um outro recurso importante é a ferramenta Meu Espaço, concebida como um local pessoal, no qual o aluno pode armazenar seus trabalhos, links favoritos, músicas, fotos, textos, etc. , de forma organizada em pastas seguindo a metáfora "windows explorer". O Meu Espaço é um ferramenta que também é "sensível ao contexto". Assim, se o aluno está num determinado projeto, todos os materiais guardados nela serão automaticamente armazenados na pasta referente ao projeto. Dessa forma fica intuitivo e fácil para o aluno, manter sua organização nas diferentes áreas do EDUKITO.

Por último, e apoiando o trabalho colaborativo, foi projetada a ferramenta Nosso Espaço, que seguindo a metáfora do Meu Espaço permite que alunos que constituem um grupo possam compartilhar arquivos, sendo possível qualquer dos participantes inserir, editar e/ou apagar arquivos para o grupo. Como um aluno pode participar em mais de um grupo, a ferramenta Nosso Espaço é personalizada para cada grupo, podendo alternar de forma simples entre os grupos.

\section{Considerações Finais}

O projeto encontra-se em fase final de desenvolvimento e teste, uma das características que desejamos preservar em todo o ambiente é a simplicidade da interface gráfica, mantendo a mesma disposição de cores, ícones grandes (com texto para alfabetizados e desenhos para os não alfabetizados), pouca poluição visual na interface para evitar distração nos detalhes e textos com fonte grande para facilitar a leitura.

Como mencionamos, o EDUKITO, foi inspirado TelEduc, mas diferencia-se dele, pela proposta de trabalho por projetos. O EDUKITO está embasado numa pedagogia globalizadora, que evita a fragmentação do conhecimento em disciplinas ou módulos e que pretende centrar-se nos interesses e necessidades do aluno. Assim, o nosso ambiente pode contribuir para uma educação inclusiva, na qual todos os envolvidos (pais, alunos, professores) possam interagir, respeitando as diferenças, 
conhecendo outras pessoas, sem discriminação e tendo o suporte tecnológico e pedagógico necessário mas promovendo a autonomia do aluno ao longo dos projetos. Nesse sentido, o EDUKITO, mantém-se fiel à metodologia de trabalho que apoia as atividades do NIEE e da Ong REDESPECIAL-BR, embasada na construção e uso de ambientes digitais/virtuais construtivistas, como um recurso para ampliar a comunicação, a linguagem, a autonomia e as trocas entre sujeitos, na construção de conhecimento, visando o seu desenvolvimento nas dimensões cognitivas e sócioafetivas. Pois, o uso da tecnologia não fica restrita ao conhecimento procedimental de manuseio, mas na sua utilização como meio para o desenvolvimento integral do sujeito. O papel do mediador é de articulador/facilitador visando o desenvolvimento cognitivo e social dos sujeitos através de atividades socialmente relevantes, que poderão propiciar novas descobertas (Passerino e Santarosa, 2002).

Finalmente queremos destacar que a educação inclusiva, traz benefícios para a sociedade e para todos os envolvidos (pais, alunos, professores) pois propicia a criação de uma sala de aula que respeita as diferenças, e na qual os indivíduos aprendem a respeitar, compreender e admirar as qualidades de todas as pessoas, independentes de suas diferenças físicas e cognitivas. Estes esforços e ações, levam em si, a idéia de uma individualização da educação, para centrar suas atividades no aluno e suas necessidades, sem deixar de lado, evidentemente a questão do professor. A interação propiciada com os colegas, desenvolve não somente habilidades cognitivas, mas também afetivas e de comunicação, pois

\begin{abstract}
"La enseñanza 'especial' debe perder su carácter 'especial' y entonces pasará a ser parte de la labor educativa común. Debe seguir el rumbo de los intereses infantiles. La escuela auxiliar, creada sólo como ayuda a la escuela normal, no debe romper nunca ni em nada los vínculos com ella.... Orientarse hacia la norma, desterrar por completo todo lo que agrava el defecto y el retraso...”(Vygotsky, 1997, p.93)
\end{abstract}

\title{
4. Notas do Texto
}

[1] A definição da Política Nacional de Educação Especial foi um importante marco qualitativo, no processo de evolução da atenção educacional pública à pessoa com necessidades especiais, no sentido de favorecer o respeito e o cumprimento dos compromissos assumidos na Conferência Mundial sobre Educação para Todos, em Jomtien, Tailândia (em 1990)

[2] Alguns muito renomeados como o NIED - Núcleo de Informática na Educação. da UNICAMP, coordenado pelo Dr. José Valente, o Laboratório de Neuropsicolingüística Cognitiva Experimental do Instituto de Psicologia da USP, coordenado pelo Dr. Fernando Capovilla que dedica-se a pesquisas e desenvolvimentos na área de comunicação alternativa e comunicação aumentativa e o LEC - Laboratórios de Estudos Cognitivos da UFRGS, coordenado pela Dra. Léa Fagundes, que desenvolveu alguns trabalhos na área de educação especial

[3] No presente trabalho denominaremos Ambiente Digital de Aprendizagem (ADA), àquele ambiente de acordo com Jonassen (1999) que se constitue num espaço no qual os sujeitos participam de um processo construtivista de ensino e aprendizagem, 
caracterizando-se por ser ativo, no sentido de permitir o controle do processo pelo aluno, construtivo, no sentido do aluno poder construir seus próprios modelos mentais e crenças com relação ao objeto em estudo, reflexivo propiciando espaço para a reflexão sobre a ação do aluno, complexo, evitando o conhecimento "fragmentado", contextualizado, pois aprender sobre algo, é aprender dentro de um contexto e colaborativo, propiciando o diálogo, a troca de experiências, o trabalho em grupo pela colaboração, a argumentação, o consenso e a discussão.

[4] O termo projeto embora tenha surgido no século XV é somente no século passado que toma a concepção que se conhece atualmente (Boutinet, 2002). A noção de projeto foi transferida para a área educacional através de Dewey que em 1886 realizava suas primeiras experimentações nesse método. Mas foi Kilpatrick, seu discípulo, que tornouse o divulgador da idéia de Dewey (Zabala, 1998).

\section{Referencias Bibliografia}

BOUTINET, J.P. Antropologia do Projeto. Porto Alegre: ArtMed, 2002.

EVANS, P. Algumas implicações da obra de Vygotsky na Educação Especial. In:

JONASSEN, D. et alli. Learning with Technology. A constructivist perspective. New Jersey: Prentice Hall, 1999.

MARCHESI, A. e MARTIN, L. Da terminologia do distúrbio às necessidades educacionais especiais. IN: COLL, César; PALÁCIOS, Jesús e MARCHESI, Álvaro (Org.) Desenvolvimento Psicológico e educação: necessidades educativas especiais e aprendizagem escolar Porto Alegre: Artes Médicas, 1995. v.3, p. 7 - 23.

PASSERINO, L. e SANTAROSA L.M C. REDESPECIAL-BRASIL e Universidade Luterana do Brasil, um relato de experiência. In: III Congresso Iberoamericano de Informática na Educação Especial 2002 - CIEE2002. Fortaleza, 2002.

SANTAROSA, L.M.C. Novos desafios para Educação na criação de ambientes de aprendizagem Telemáticos. Anais da I Conferência Internacional de Tecnologias da Informação e da Comunicação - Challenges'99. Portugal - Braga - maio/99 - 74-75

SANTAROSA, L. M. C. PASSERINO, L. M., CARNEIRO, M. L., GELlER, M. Formação de Professores a Distância e em Serviço: Ambiente TelEduc no Projeto Nacional de Informática na Educação Especial do MEC. In: Revista Informática na Educação: Teoria e Prática, v. 4 n. 2,Dezembro, 2001.

SEESP - Secretaria de Educação Especial. Educação para todos - EFA 2000. Avaliação: Políticas e Programas governamentais em educação especial. 2000. Disponível na Internet http://www.mec.gov.br. Consultado em 03/05/2001.

VYGOTSKY, L. S Obras Escogidas: Fundamentos de Defectologia. Tomo V. Madrid: Visor, 1997.

ZABALA, A. A Prática Educativa: como ensinar. Porto Alegre: ArtMed, 1998. 